\title{
Runoff modeling of the Mara River using Satellite Observed Soil Moisture and Rainfall
}

\author{
J. Mwania $^{1 *}$, R. van der Velde ${ }^{1}$, Z. Vekerdy $^{1}$, J. Mtamba $^{2}$ \\ ${ }^{1}$ University of Twente - ITC, Enschede, Netherlands \\ ${ }^{2}$ University of Dar es Salaam, Dar es Salaam, Tanzania \\ *Corresponding author: Jonathan Muithya Mwania; email: mwania3@yahoo.com
}

\begin{abstract}
Hydrological models are essential in water resources management. However modeling in poorly gauged catchments is a big challenge. Recent studies have shown that satellite based hydrological and meteorological data has the potential of being part of the solution towards overcoming this challenge. In this study, we modify the conceptual lumped rainfall-runoff model by Meier et al. (2011) to simulate the runoff of the Mara River basin. The model is developed based on the relationships found between satellite observed soil moisture and rainfall and the measured runoff. It uses the satellite observed rainfall as the prime forcing, and the soil moisture to separate the fast surface runoff and slow base flow contributions. The soil moisture and rainfall products used in this research are the Advanced Scatterometer Soil Water Index (ASCAT SWI) and Tropical Rainfall Measurement Mission (TRMM) 3B42 v7 respectively. The performance of the model is evaluated for three sub-catchments defined by the Mara mines, Nyangores and Amala gauging stations along the Mara River. The Pearson correlation (r) for Mara mines Nyangores and Amala during calibration and (validation) were $0.54(0.77), 0.67(0.74), 0.125(0.48)$ respectively. The model showed great potential for simulating dry season runoff, but needs further improvement to be able to reliably simulate wet season runoff. Nevertheless, this study demonstrates the potential role operational satellite based soil moisture and rainfall products can play in quantifying the available water resources particularly in the many un-gauged river basins across Africa.
\end{abstract}

Keywords-ASCAT SWI, hydrological modeling, rainfall, runoff, soil moisture, TRMM 3B42 v7 


\section{INTRODUCTION}

Recent studies on the use of satellite observed soil moisture for hydrological modeling have shown that these products have great potential in contributing to the management of the water resources in poorly gauged catchments (Scipal et al., 2008; Brocca et al., 2010; Draper et al., 2011; Matgen et al., 2012;). In particular, Scipal et al. (2005) used regression equation of best fit relationship between runoff and soil moisture observed with European Remote Sensing (ERS) Scatterometer in modeling runoff of the Zambezi river basin. Khan et al. (2012) found a Pearson correlation coefficient of 0.9 between measured runoff of Okavango river basin (South Africa) and Advanced Microwave Scanning Radiometer for Earth Observation System (AMSR-E) observed soil moisture. Meier et al. (2011) further developed the concept by introducing rainfall as a forcing data in modeling runoff of the Zambezi River basin. The authors built the model on the basis of the relationship found between ERS Scatterometer observed soil moisture, Famine Early Warning System Network (FEWS NET) rainfall product and in-situ measured runoff.

While Meier et al. (2011) did their runoff simulations on a ten day time-step, in this study we do the simulations on a daily time step using different rainfall and soil moisture satellite products. The study area is the Mara River basin. The basin is a sub-catchment of the Lake Victoria basin that is in turn part of the larger Nile River Basin. It covers an area of $13,750 \mathrm{~km}^{2}$ in South Western Kenya and North Western Tanzania (see figure 1). In the upper parts of the basin is the Mau Forest where the Mara River originates from at an attitude of about 3,000 $\mathrm{m}$ above sea level (m.a.s.1.). The forest is the key water tower and source region for also other rivers including Sondu, Njoro and Ewaso Ng'iro rivers. Mara River flows to the southwest over a stretch of $395 \mathrm{~km}$ before draining into Lake Victoria at Musoma in Tanzania at an attitude of about 1,000 m.a.s.l. The river has two main perennial tributaries in the upstream part, namely the Nyangores and Amala Rivers. In the middle parts of the basin is the tropical savannah vegetation which supports the unique Mara-Serengeti ecosystem, famous for the scenic large scale seasonal wildebeest migration. In the south-western parts is the 
Mara Wetlands ecosystem. According to Dessu and Mellesse (2012), a third of available arable land in Mara River basin is under small scale farming.

Previous studies have shown that the flow regime of the Mara River has been changing. A study on the impacts of land use/cover on the hydrology of the river by Mati et al. (2008) using Geospatial Stream Flow Model (GeoSFM) showed out that the peak flows have increased by 7\% for the period between 1973 and 2000. Using Landsat images, they also highlighted changes in land cover/use over the same period. Notably, the extents of agricultural and wetland areas have increased by $203 \%$ and $387 \%$ while the savannah vegetation and forest areas have reduced by $79 \%$ and 32\% respectively. A study by Mango et al. (2011) showed that conversion of forest areas to agriculture and grasslands in the upstream of the basin was most likely reducing dry season flows, while increasing quick peak flows. Human activity in the basin is affecting both the flow regime and the water quality of the Mara River (Gereta et al., 2009). A study by Juston et al. (2013) using 44 years of historical data detected a reduction in the lowest base flow.

\section{MATERIALS AND METHODS}

\subsection{In-situ measurements}

Runoff data was utilized for validation and calibration of the soil moisture-runoff model. The data was obtained for Mara River at Mara mines, Nyangores at Bomet and Amala at Mulot river gauging stations (see table 1 and figure 1). Analysis of historical data over the period of 1970 to 1996 from the Mara mines, Nyangores and Amala at Mulot by Dessu \& Mellesse (2012) shows a mean discharge of $33.9 \mathrm{~m}^{3} \mathrm{~s}^{-1}, 8.4 \mathrm{~m}^{3} \mathrm{~s}^{-1}$ and $9.9 \mathrm{~m}^{3} \mathrm{~s}^{-1}$ with standard deviations of $60 \mathrm{~m}^{3} \mathrm{~s}^{-1}, 7.1 \mathrm{~m}^{3} \mathrm{~s}^{-1}$ and $19.9 \mathrm{~m}^{3} \mathrm{~s}^{-1}$ respectively. The three stations were rehabilitated and installed with automatic recording systems in 2012 (Mtamba et al., 2013).

The in-situ measured rainfall was used to investigate the reliability of the satellite rainfall product. Out of the forty-four stations, within and around the basin only six (see figure 1 and table 1) had sufficient data falling within the time span of the selected satellite rainfall data used in this study. The basin has bi-modal annual 
rainfall distribution with the long rainy season from March till June and the short season in November and December. The mean annual rainfall varies from $1,000 \mathrm{~mm}$ to $1,750 \mathrm{~mm}, 900 \mathrm{~mm}$ to $1,000 \mathrm{~mm}$ and $300 \mathrm{~mm}$ to $800 \mathrm{~mm}$ in the upper, middle and lower parts of the basin respectively (Dessu et al., 2014; Dessu \& Mellesse, 2012).

Figure 1: Map of the Mara River Basin processed from Shuttle Radar Topographic Mission Digital Elevation Model. The map shows the location of both river and rain fall gauging stations used in this research

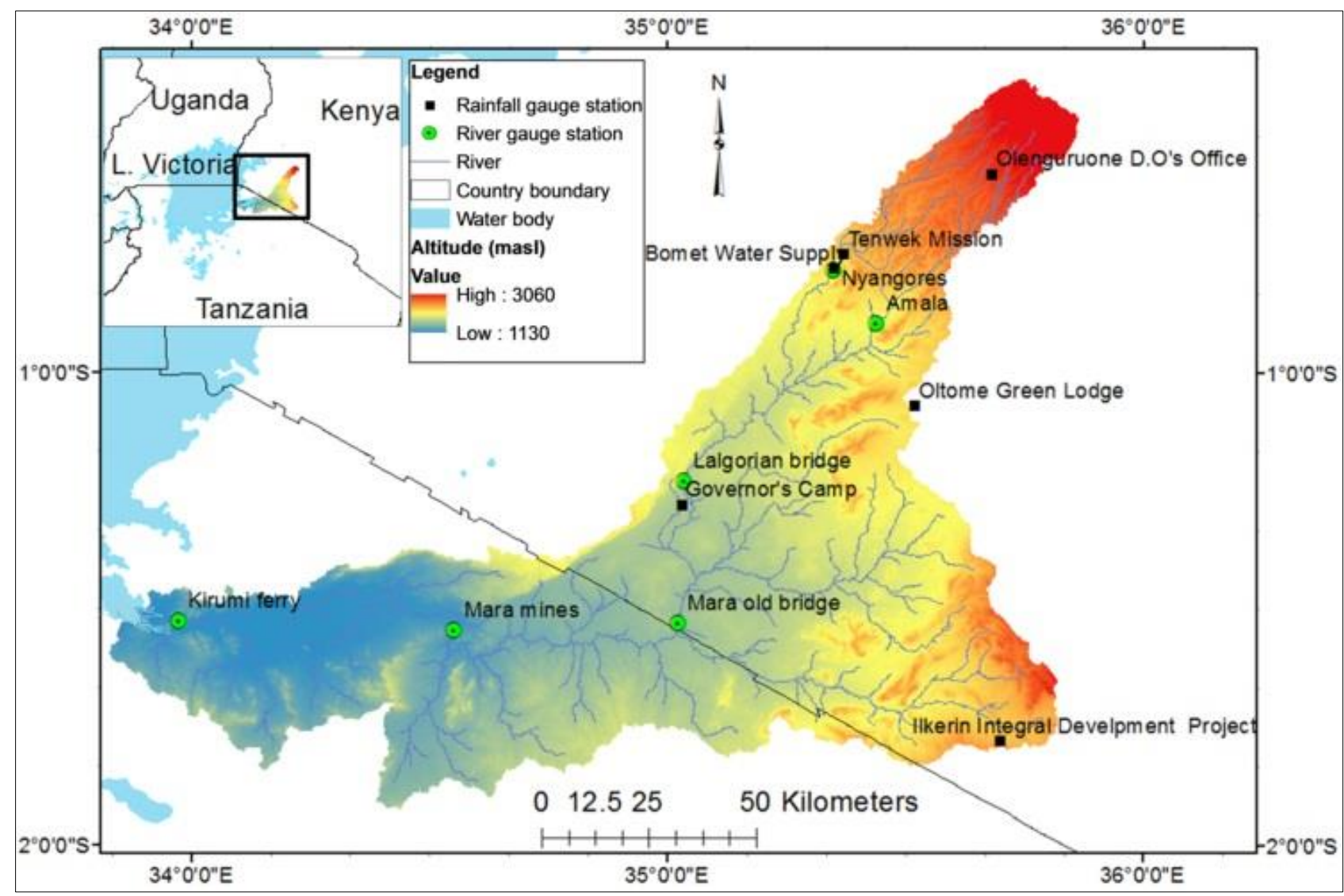

TABLE 1: RIVER AND RAINFALL GAUGING STATIONS USED IN THIS STUDY

$\begin{array}{cccc}\text { Station } & \text { Longitude } & \text { Latitude } & \text { Start } \\ \text { code } & \left({ }^{0} E\right) & \left({ }^{0} S\right) & \text { Year }\end{array}$


River Gauge Station

\begin{tabular}{|c|c|c|c|c|}
\hline Nyangores & 1LA03 & 35.35 & -0.79 & 1963 \\
\hline Amala & 1LB02 & 35.43 & -0.89 & 1955 \\
\hline Lalgorian bridge & ILA04 & 35.04 & -1.23 & 1970 \\
\hline Mara Mine & $5 \mathrm{H} 2$ & 34.55 & -1.55 & 1969 \\
\hline Kirumi ferry & $5 \mathrm{H} 3$ & 33.86 & -1.51 & 1969 \\
\hline \multicolumn{5}{|l|}{ Rainfall Gauge Station } \\
\hline \multirow[t]{2}{*}{ Tenwek Mission - Sotik } & 09035079 & 35.37 & -0.75 & 1959 \\
\hline & 09035085 & 35.68 & -0.58 & 1959 \\
\hline \multicolumn{5}{|c|}{ Olenguruone D.O's Office - Molo } \\
\hline Bomet Water Supply & 09035265 & 35.35 & -0.78 & 1966 \\
\hline Oltome Green Lodge - Narok & 09135004 & 35.52 & -1.07 & 2001 \\
\hline Ilkerin Integral Development & 09135025 & 35.70 & -1.78 & 1973 \\
\hline \multicolumn{5}{|l|}{ Project } \\
\hline Governor's Camp & 09135026 & 35.03 & -1.28 & 1973 \\
\hline
\end{tabular}

\subsection{Satellite data}

The satellite soil moisture product used in this study is the Soil Water Index (SWI) developed at the Vienna University of Technology. The product is calculated from Advanced Scatterometer (ASCAT) sensor generated surface soil moisture (SSM) data following the concept of a two-layer force-restore model described in Wagner et al. (1999b). The SWI is available on a temporal and spatial resolution of 1 day $12.5 \mathrm{~km}$ respectively.

The satellite rainfall product used in this research is the Topographic Rainfall Measurement Mission (TRMM) 3B42 version 7. The product is used as the prime forcing for the model. TRMM is a joint mission of National Aeronautics and Space Administration (NASA) and Japan Aerospace Exploration Agency 
(JAXA) for measuring tropical and subtropical rainfall. The mission employs various instruments including the TRMM Microwave Imager (TMI), Cloud and Earth Radiant Energy Sensor (CERES), Precipitation Radar (PR) and Lightning Imaging Sensor (Liu et al., 2012; NASA, 2011). The product is available with a $0.25^{\circ} \mathrm{x}$ $0.25^{\circ}$ resolution for latitudes between $50^{\circ} \mathrm{N}$ and $50^{\circ} \mathrm{S}$ (NASA, 2011).

\subsection{Runoff Model}

Scipal et al. (2005) formulated the Basin Water Index (BWI) as spatially averaged SWI. Its values range from 0 - 1 with 0 signifying a completely dry basin with all the rainfall infiltrating, and 1 , a completely saturated basin with constant infiltration. Building upon this research Meier et al. (2011) proposed a lumped process based runoff model that can be solely driven with data products derived from Earth Observations and uses the BWI as measure for the soil water storage and rainfall as the prime forcing. In this study we apply a modified version of the Meier et al. (2011) model. The model structure includes two linear storage reservoirs, namely surface and subsurface storage layer. The model has been modified by reducing the model parameters and replacing the delay factor with a low pass filter approach. The low pass filter attenuates the storage components as a function of time before they are routed as runoff. In this new approach, the contribution of previous rainfall events is factored. The reasoning is that contribution of a particular rainfall event to runoff is not instantaneous but rather increases exponentially over a given time before reaching a peak value. The concept of the model is that BWI separates rainfall into surface and groundwater runoff production pathways expressed as follows:

$I_{G W}=k R(t)(1-B W I(t))$

Where, $I_{G W}$ is infiltration to the subsurface storage $\left(m \cdot d^{-1}\right), R$ is rainfall $\left(m m \cdot d^{-1}\right), k$ is a model parameter $\left(d^{-1}\right)$ accounting for losses (for instance, interception and evapotranspiration) and $t$ is the model time step (d) (Meier et al., 2011). $k$ of 1 indicates a situation with zero losses, a case where rainfall is equal to runoff and $k$ of 0 indicates a case where all the rainfall is lost hence no runoff. As the soil becomes more saturated, more rainfall 
is routed through surface storage. Similarly as the soil becomes less saturated, less rainfall is routed through subsurface storage.

The surface and groundwater storage change is calculated across a time step as follows,

$$
\begin{gathered}
\frac{\Delta S_{S}(t)}{\Delta t}=k R(t) B W I(t)-I_{G W}-S_{S}(t-1) \\
\frac{\Delta S_{G W}(t)}{\Delta t}=\max \left(I_{G W} ; 0\right)-S_{G W}(t-1)
\end{gathered}
$$

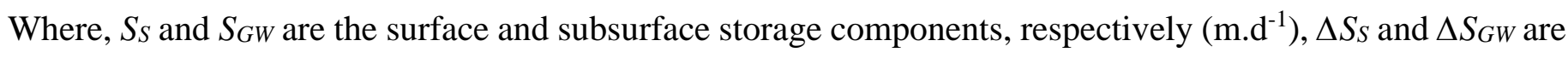
the change in surface storage and subsurface storage components, respectively $\left(\mathrm{m}^{-1} \mathrm{~d}^{-1}\right)$. These surface and groundwater storage change equations are linked to their respective water budget as follows,

$$
\begin{aligned}
& S_{S}(t)=\frac{\Delta S_{S}(t)}{\Delta t}+S_{S}(t-1) \\
& S_{G W}(t)=\frac{\Delta S_{G W}(t)}{\Delta t}+S_{G W}(t-1)
\end{aligned}
$$

The runoff components are subsequently computed from the storage components as follows,

$$
\begin{gathered}
Q_{S}(t)=\frac{\sum_{i=(t-1)}^{n} S_{S} e^{-(t-i) / \tau}}{\sum_{i=(t-1)}^{n} e^{-(t-i) / \tau}} \\
Q_{G W}(t)=\frac{\sum_{i=(t-1)}^{n} S_{G W} e^{-(t-i) / \tau_{G W}}}{\sum_{i=(t-1)}^{n} e^{-(t-i) / \tau_{G W}}} \\
Q(t)=Q_{S}(t)+Q_{G W}(t)
\end{gathered}
$$

Where: $Q_{s}$ and $Q_{G W}$ are the surface and groundwater runoff components respectively; and $\tau$ and $\tau_{G W}$ are the characteristic catchment response times $(d)$ related to the surface and groundwater runoff respectively. This set of equations is schematically represented in Figure 2. 
Figure 2: The input in this set up is rainfall. The level of BWI determines the distribution of rainfall between the surface and subsurface storage compartment. As the BWI increases, infiltration reduces and more rainfall is routed to the surface storage

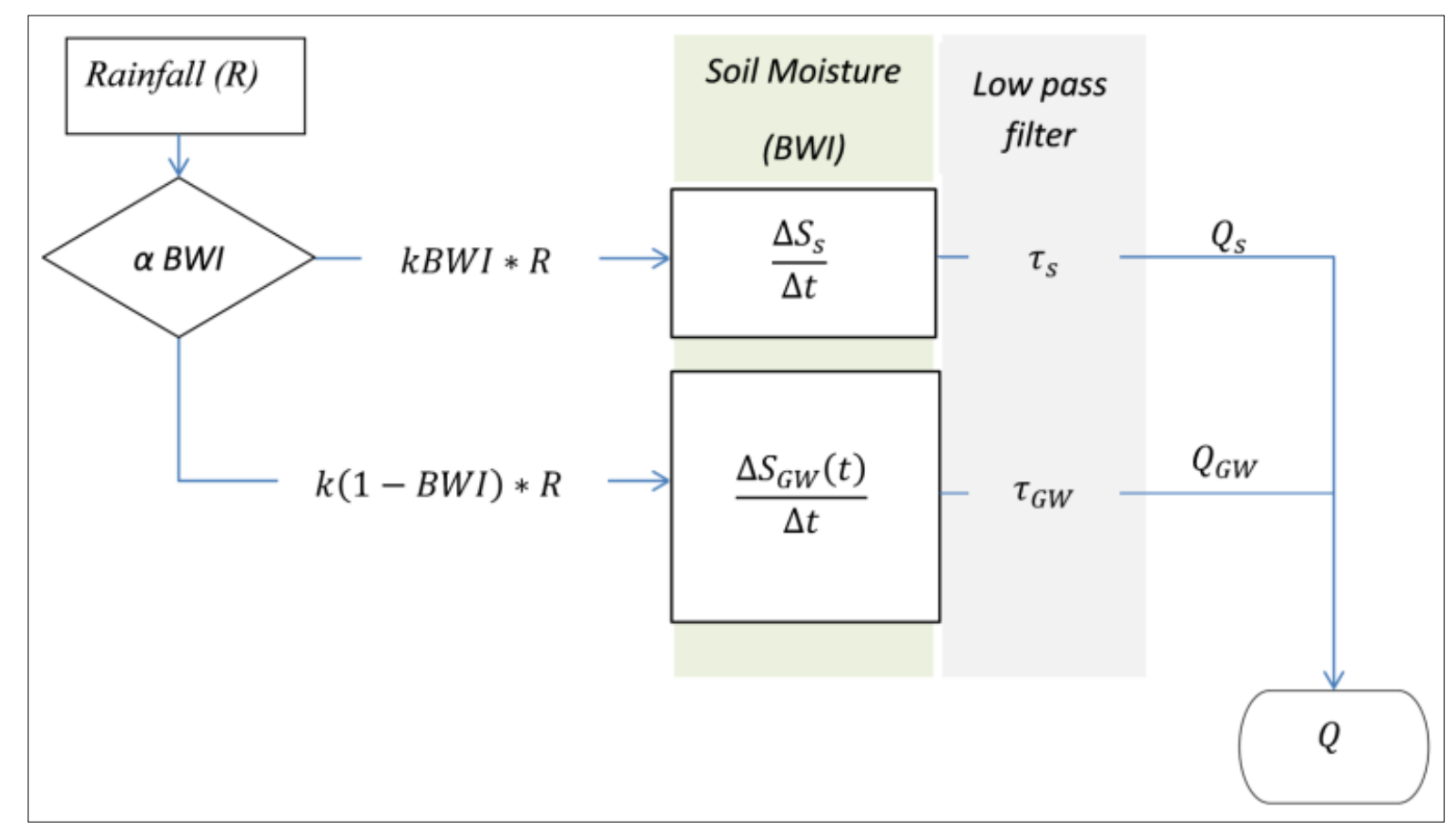

\section{RESULTS}

\subsection{Relationships between rainfall, runoff and BWI}

The relationship of rainfall, runoff and BWI was investigated quantitatively using coefficient of determination $\left(R^{2}\right)$. The investigation period was from January 2007 to July 2013 . The best fitting trend line for BWI plotted against TRMM was found to be logarithmic. The results of the analysis including the $R^{2}$ for the three sub-catchments namely Mara mines, Nyangores and Amala are illustrated in figure 3. In the analysis, monthly averages of BWI and TRMM rainfall were used.

Figure 4 illustrates the relationship of runoff-BWI including the $R^{2}$ for the three sub-catchments using monthly averages. The best fitting trend line for this relationship was found to be exponential. 
Figure 3: BWI versus TRMM scatter plots for Mara mines, Nyangores and Amala sub-catchments. The data is monthly means.

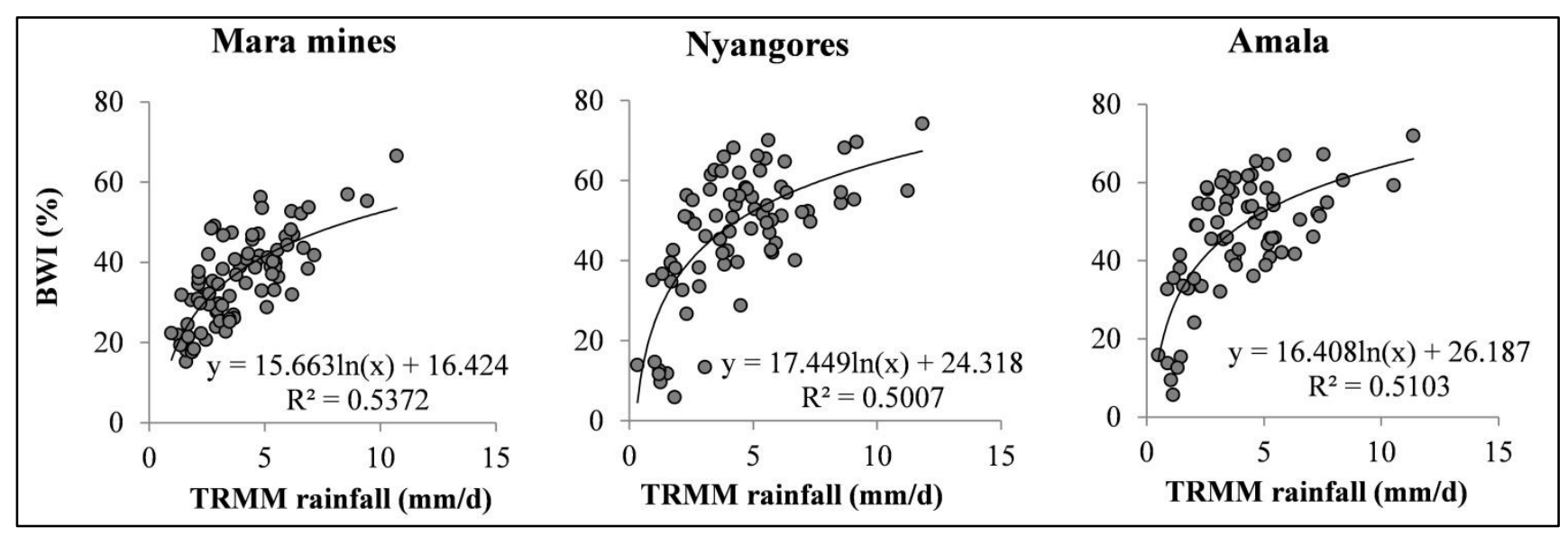

Figure 4: Runoff versus BWI scatter plots for Mara mines, Nyangores and Amala sub catchments. The data is monthly means.

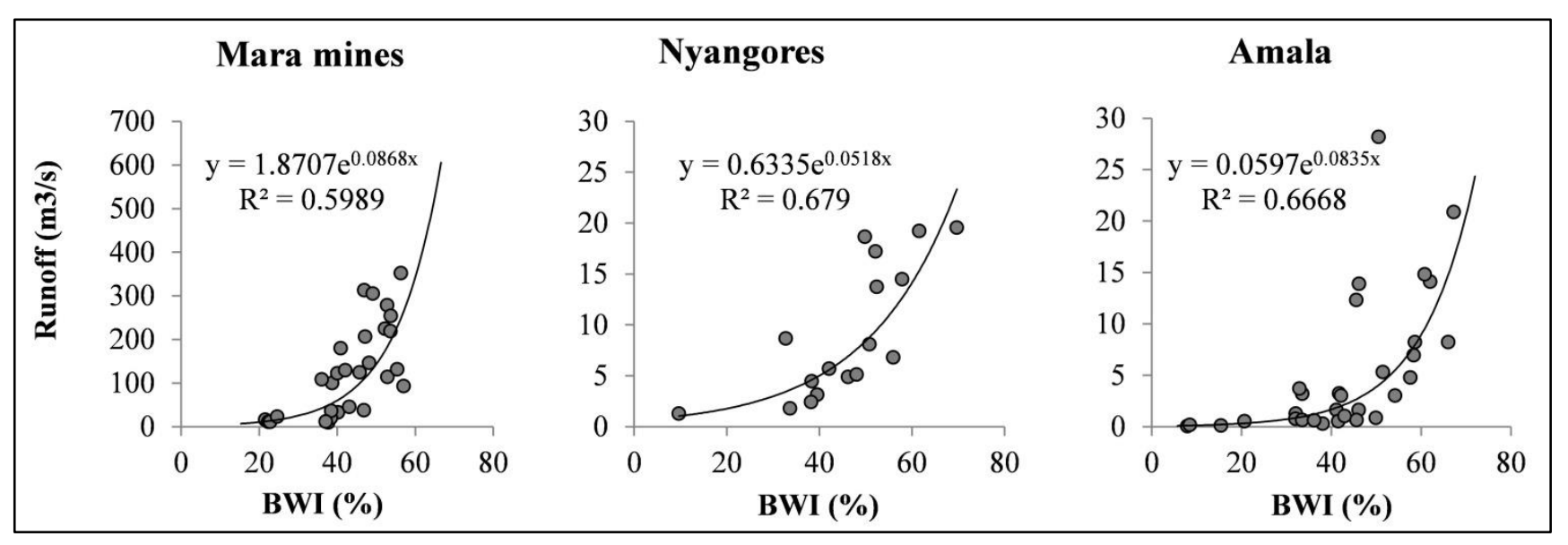

\subsection{Calibration}

Calibration of the $k$ parameter was done separately for Mara mines, Nyangores and Amala sub-catchments. The catchment response time $\tau_{s}$ and $\left(\tau_{G W}\right)$ for Mara mines, Nyangores and Amala were fixed at: 3 days (200 days); 1 days (100 days) and; 1 day (100 days) respectively. These values are assumed taking into consideration the size of the given sub-catchment and field observations. For each of the three sub-catchments, different calibration periods and durations had to be used due to the large data gaps. The periods were selected to include at least one wet season. The results of the calibration process are shown in table 2. 


\subsection{Validation}

Validation was performed by running the model with the respective optimised $\mathrm{k}$ parameter and the $\tau \mathrm{s}$ and ( $\tau \mathrm{GW})$ for Mara mines, Nyangores and Amala sub-catchments. Different validation periods and durations had to be selected for each sub-catchment due to large data gaps. The validation periods were selected to capture at least a wet season. The results of the validation process are shown in table 2 .

TABLE 2: CALIBRATION AND VALIDATION RESULTS FOR MARA MINES, NYANGORES AND AMALA

\begin{tabular}{|c|c|c|c|c|}
\hline & units & Mara mines & Nyangores & Amala \\
\hline \multicolumn{5}{|l|}{ Calibration } \\
\hline$k$ parameter & $\mathrm{d}^{-1}$ & 0.074 & 0.157 & 0.179 \\
\hline$\tau S$ & $d$ & 3 & 1 & 1 \\
\hline$\tau_{G W}$ & $\mathrm{~d}$ & 200 & 100 & 100 \\
\hline RMSE & $\mathrm{m}$ & 0.00034 & 0.00025 & 0.00081 \\
\hline MAE & $\mathrm{m}$ & 0.0002 & 0.00018 & 0.00058 \\
\hline Bias & $\mathrm{m}$ & 0.00052 & 0.01184 & 0.027 \\
\hline$r$ & - & 0.54 & 0.67 & 0.125 \\
\hline \multicolumn{5}{|l|}{ Validation } \\
\hline$\overline{\text { RMSE }}$ & $\mathrm{m}$ & 0.00094 & 0.00132 & 0.00176 \\
\hline MAE & $\mathrm{m}$ & 0.00051 & 0.00121 & 0.00079 \\
\hline Bias & $\mathrm{m}$ & 0.048 & 0.186 & 0.062 \\
\hline$r$ & - & 0.77 & 0.74 & 0.48 \\
\hline
\end{tabular}


Long term runoff simulations were done for the period from January 2007 to July 2013 on a daily time step for each of the three sub catchments. Over the period, there was no notable change in the flow regime. Figure 5 shows the measured and simulated total runoff for the three sub catchments. Figure 6 shows monthly cumulated surface and groundwater runoff simulations. Quantitative analysis of the simulations showed that Nyangores, Amala and Mara mines sub-catchments generate 54\%, 32\% and 14\% respectively of the total runoff generated in the Mara River basin.

Figure 5: Long term runoff simulations on a daily model time step for Mara mines, Nyangores and Amala sub catchments. The simulation period is from January 2007 up to July 2013

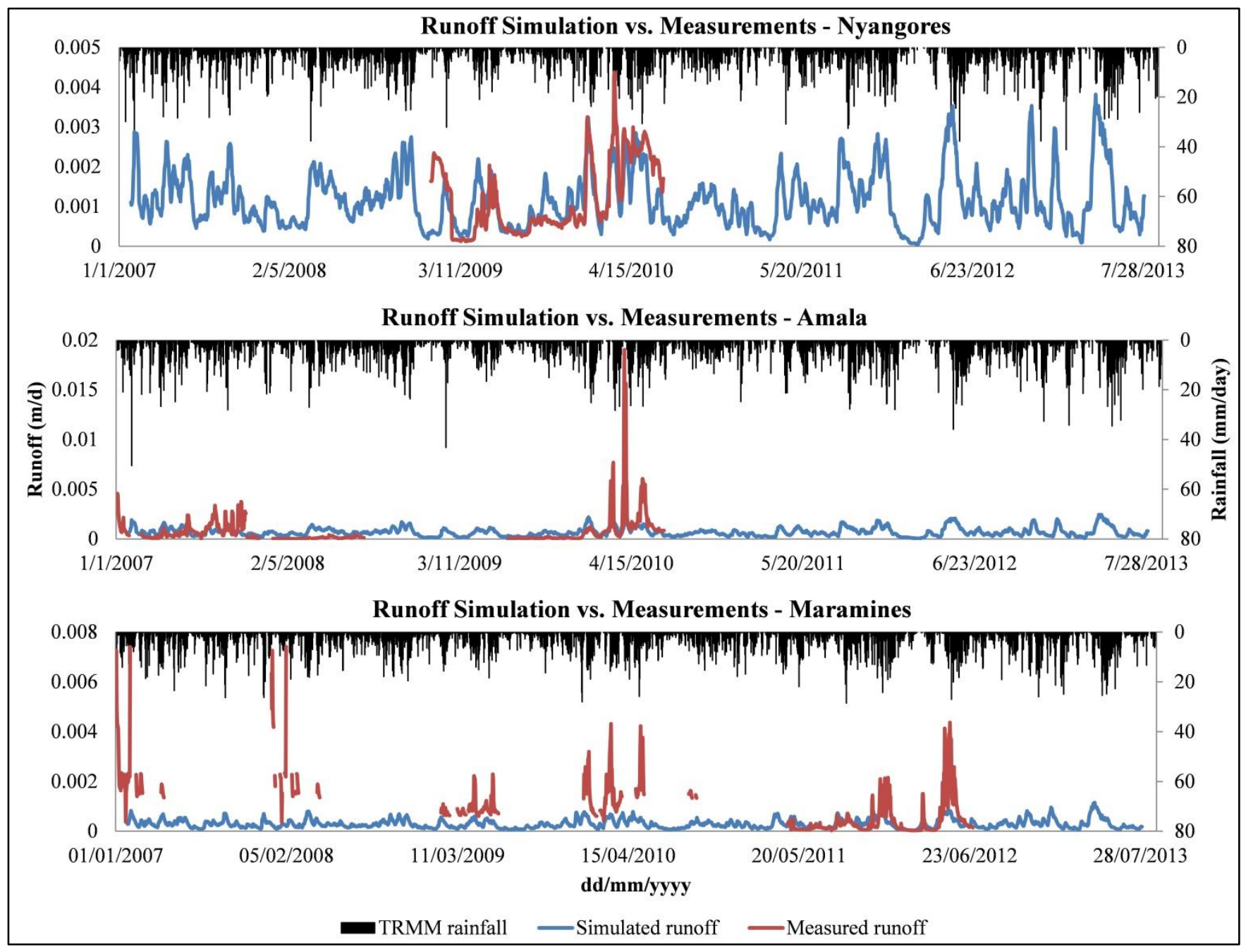


Figure 6: Comparison monthly summations of simulated surface and groundwater runoff components for Mara mines, Nyangores and Amala sub catchments. The simulation period is from January 2007 up to July 2013.

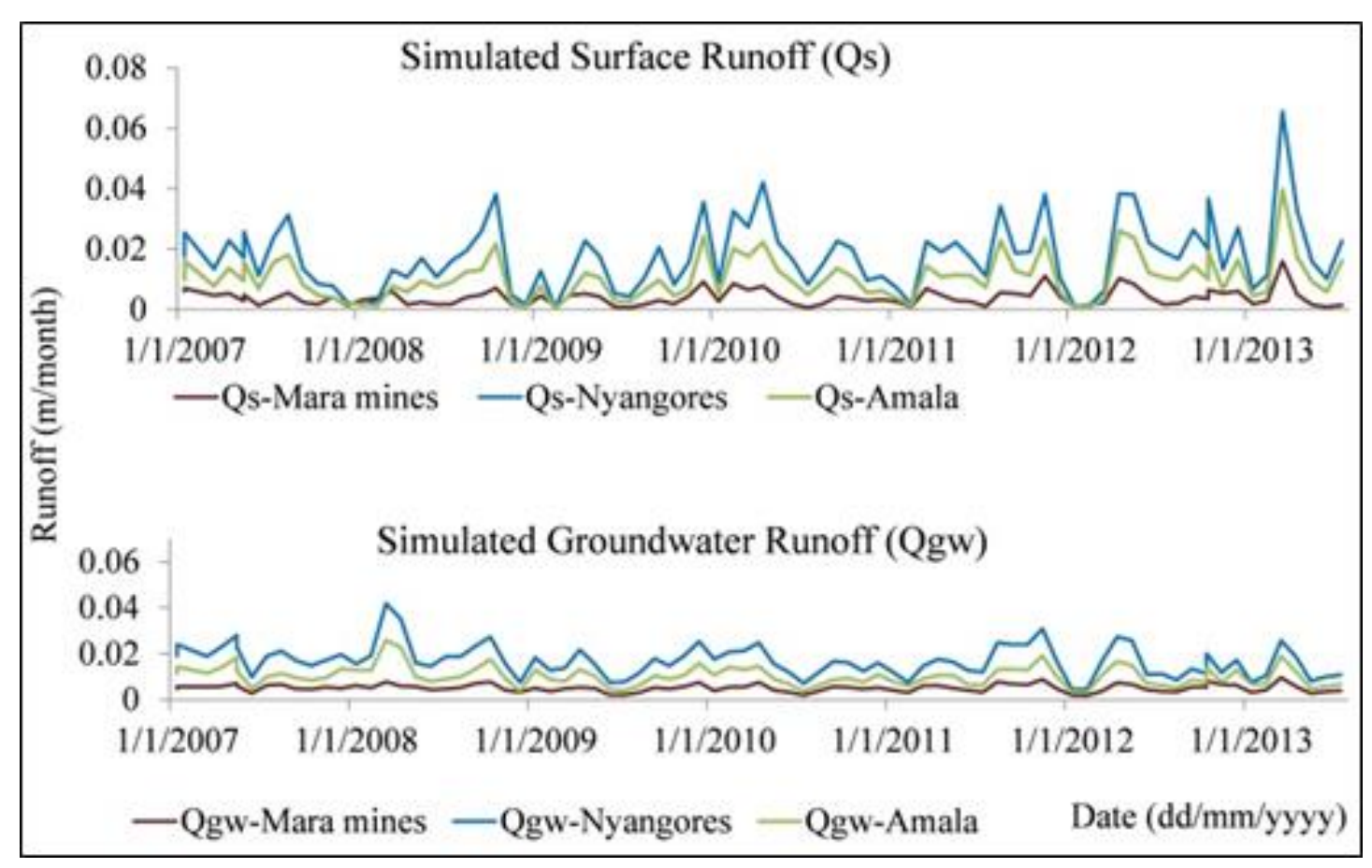

\section{DISCUSSION}

From the analysis of the relationship between BWI and rainfall, it can be seen that as BWI and rainfall increases the scatter of the data points increases also (figure 3). This is because as the rainfall increases, soil moisture continues increasing until the soil is completely saturated $(\mathrm{BWI}=1)$. At this point, infiltration is at maximum capacity and any further increase in rainfall intensity leads to increase in contribution to surface runoff. This is supportive of the concept used in the Meier et al. (2011) runoff model. Although the shape of the BWI-rainfall relationships is the same for all the sub-catchments, the steepness of the curves is different for each. Mara mines is observed to have lower BWI peak values compared to the other sub-catchments. This can be attributed to catchment characteristics. Mara mines sub-catchment has significant semi-arid regions typically associated with high ET compared to Nyangores and Amala that are situated at a higher altitude with 
higher forest land cover. It can be argued that there is higher infiltration in Nyangores and Amala thus supporting the arguments by previous studies which attribute the high infiltration in the two sub-catchments to their relatively higher forest cover as compared to Mara mines (Dessu et al., 2014; Dessu \& Mellesse, 2012; Gereta et al., 2009; Mango et al., 2011; Mati et al., 2008).

The plots of runoff versus BWI (figure 4) show that runoff increases exponentially as BWI increases. This is so because when the soil is dry (low BWI) little runoff is being produced in response to rainfall. The runoff production increases exponentially as the BWI increase because of reduction in the infiltration capacity. This observation confirms that the findings of Meier et al. (2011) and Scipal et al. (2005) are also valid for the Mara River basin. The steepness of the curves of the relationship of runoff and BWI are taken as a measure of the storage capacity in the catchment with very steep slopes indicating a low storage capacity. With this assumption, Mara mines is shown to have lower storage capacity compared to the other sub catchments. Comparing Nyangores and Amala, Amala is shown to have a steeper slope as BWI increases. Amala is also shown to have a relatively gentle slope for lower BWI compared to Nyangores. This may be an indication of lower flow rates during dry seasons in comparison to Nyangores. These results support the findings by previous studies that Nyangores and Amala have higher storage capacities which serves to sustain Mara river during dry seasons, (Dessu et al., 2014; Dessu \& Mellesse, 2012; Mango et al., 2011; Mati et al., 2008).

The value of model parameter $k$ for Mara mines is notably lower compared with the other sub catchments. This indicates that there are more losses within Mara mines compared to Nyangores and Amala. Amala has the highest $k$ compared to Nyangores. The difference in $k$ for the two can be attributed to land cover. Nyangores has more land cover than Amala(Mango et al., 2011; Mati et al., 2008). It can, thus, be assumed that few losses due to ET occur in Amala as most of the rainfall is drained as quick runoff.

The model does not simulate the peak flows very well, especially for the Amala and Mara mines (figure 5). Notably, at Nyangores the model was able to fairly simulate the peak flows. This supports the arguments of Meier et al. (2011) that this model is not suitable for catchments with relatively low storage capacity and quick 
peak runoffs. It is also observed that the model initially overestimates runoff in all the three sub-catchments. It can be argued that initially the soil may be dry hence less runoff, a situation not taken into consideration in the model design. Dessu and Mellesse (2012) in their study on modeling rainfall runoff processes in the Mara River basin using Soil and Water Assessment Tool (SWAT), found that Amala sub catchment was consistently giving poor simulation results. They attributed the poor results to uncertainties in either measured rainfall or measured runoff input data.

Quantitative analysis of simulated surface and groundwater runoff shows that Nyangores generates more surface and groundwater runoff per unit area compared to the other sub catchments. Mara mines is observed to have the lowest surface and groundwater runoff generation per unit area. This may be an indication of relatively higher losses in the sub-catchment. This further supports our argument that there is apparently higher infiltration in Nyangores compared to the other sub catchments. This is also in agreement with previous studies which indicate that Nyangores has higher base flows than Amala(Dessu et al., 2014; Dessu \& Mellesse, 2012; Mango et al., 2011; Mati et al., 2008).

\section{CONCLUSION}

The overall objective of this study was to develop a runoff simulation model based on satellite observed soil moisture and rainfall as a forcing data in the MRB. The model is built on the relationship found between satellite observed soil moisture and rainfall and measured runoff. The relationship between soil moisture versus rainfall is observed to be logarithmic for Mara mines, Nyangores and Amala with $R^{2}$ of $0.54,0.5$ and 0.51 , while that of runoff versus soil moisture is exponential, with $R^{2}$ of $0.6,0.68$ and 0.67 respectively. These results are in agreement with the findings of previous similar research (Khan et al., 2012; Meier et al., 2011; Scipal et al., 2005).

In this study, the model parameter $k$ is found to be affected by catchment characteristics like for example, land cover, infiltration/groundwater storage capacity, which affects ET. Mara mines assumed to have the highest ET has the lowest $k$. Amala assumed to have the least ET has the highest $k$. The performance of the 
model is found to be affected by catchment's infiltration capacity and quality of in-situ measured runoff. The relatively good performance of the model in Nyangores is attributed to the catchment's apparent high infiltration capacity compared with the other two sub-catchments.

The model is found to be applicable in monitoring dry season runoff even in catchments with low storage capacities like Mara mines. However it has a weakness in simulating wet season flows in such catchments. We hypothesize that this can improve by the use of higher spatial resolution rainfall and soil moisture products for example from the NASA's Global Precipitation Mission and Soil Moisture Active/Passive (SMAP) mission and ESA's Sentinel-1 mission.

\section{ACKNOWLEDGMENTS}

We thank Nuffic for funding the study program leading to this research and ESA Alcantara project for partially funding the field project. We thank Water Resources Management Authority (Kenya) and Kenya Meteorological Department for providing the river discharge and rainfall data respectively. We thank Robert Becht of University of Twente and Prof. M. E. McClain of UNESCO Institute for Water Education for facilitating access to historical discharge data for the Mara River Basin. Kind regards to Richard Kidd of Vienna University of Technology for providing information on downloading satellite observed soil moisture data used in this research. Lastly we thank the chairman of Amala river branch of the Mara River Water Users Association (MRWUA) Joseph Chepusit and vice-chair Jessica Tesot for showing us around the upper and middle parts of the Basin.

\section{References}

Brocca, L., Hasenauer, S., Lacava, T., Melone, F., Moramarco, T., Wagner, W., . . Bittelli, M., (2011). Soil moisture estimation through ASCAT and AMSR-E sensors: An intercomparison and validation study across Europe. Remote Sensing of Environment, 115(12), 3390-3408.

Dessu, S. B., Melesse, A. M., Bhat, M. G., \& McClain, M. E., (2014). Assessment of water resources 
availability and demand in the Mara River Basin. CATENA, 115(0), 104-114.

Dessu, S. B., \& Mellesse, A. M., (2012). Modelling the rainfall-runoff process of the Mara River basin using the Soil and Water Assessment Tool. Hydrological Processes, 26(26), 4038-4049.

Gereta, E., Mwangomo, E., \& Wolanski, E., (2009). Ecohydrology as a tool for the survival of the threatened Serengeti ecosystem. Ecohydrology \& Hydrobiology, 9(1), 115-124.

Juston, J., Jansson, P.-E., \&Gustafsson, D., (2013). Rating curve uncertainty and change detection in discharge time series: case study with 44-year historic data from the Nyangores River, Kenya. Hydrological Processes, doi: 10.1002/hyp.9786

Khan, S. I., Hong, Y., Vergara, H. J., Gourley, J. J., Brakenridge, G. R., De Groeve, T., . . Yong, B., (2012). Microwave Satellite Data for Hydrologic Modeling in Ungauged Basins. Geoscience and Remote Sensing Letters, IEEE, 9(4), 663-667.

Liu, Z., Ostrenga, D., Teng, W., \& Kempler, S., (2012). Tropical Rainfall Measuring Mission (TRMM) precipitation data and services for research and applications. Bulletin of the American Meteorological Society, 93(9), 1317-1325.

Mango, L. M., Melesse, A. M., McClain, M. E., Gann, D., \& Setegn, S. G., (2011). Land use and climate change impacts on the hydrology of the upper Mara River Basin, Kenya: Results of a modeling study to support better resource management. Hydrology and Earth System Sciences, 15(7), 2245-2258.

Mati, B. M., Mutie, S., Gadain, H., Home, P., \&Mtalo, F., (2008). Impacts of land-use/cover changes on the hydrology of the transboundary Mara River, Kenya/Tanzania. Lakes \& Reservoirs: Research \& Management, 13(2), 169-177.

Meier, P., Fromelt, A., \&Kinzelbach, W., (2011). Hydrological real-time modelling in the Zambezi river basin 
using satellite-based soil moisture and rainfall data. Hydrology and Earth System Sciences, 15(3), 999-1008.

Mtamba J.D., Ndomba, P. M., Mtalo F. W, Crosato A., (2013). Hydraulic study of flood rating curve development in the lower Mara Basin. In 4th International Multidisciplinary Conference on Hydrology and Ecology (HydroEco 2013). Rennes, France, May 2013.

NASA. (2011). Explanation of data products retrieved 28 August 2013, from http://pmm.nasa.gov/dataaccess/data-products

Scipal, K., Scheffler, C., \& Wagner, W., (2005). Soil moisture-runoff relation at the catchment scale as observed with coarse resolution microwave remote sensing. Hydrology and Earth System Sciences, 9(3), 173-183.

Wagner, W., Lemoine, G., \&Rott, H., (1999b). A method for estimating soil moisture from ERS scatterometer and soil data. Remote Sensing of Environment, 70(2), 191-207. 